\title{
DELIBERATIONS ON CONSERVATION OF BUILT HERITAGE: PAYING HOMAGE TO A HISTORICAL PAST THROUGH ARCHITECTURAL EDUCATION, LEARNING AND RESEARCH
}

\author{
ACHILLES AHIMBISIBWE \& ANTHONY K. WAKO \\ Faculty of the Built Environment, Uganda Martyrs University, Uganda
}

\begin{abstract}
Memorialization of Africa's architectural past continues to fade in time by way of exposure to the cruelty of natural or man-made forces, iconic buildings from as recent as the 1960s are torn down with little consideration of their heritage value. In 2010, controversy surrounding the demolition of Uganda's National Museum for a proposed high-rise redevelopment brought to light the blatant disregard for thematic value of Uganda's memorable architecture. Unfortunately, this was a lone survivor among a myriad of projects where developers show no sympathy, architects offer no guidance, and research efforts draw no attention to protect built heritage or safeguard rich historical narratives. Architecture Education should adopt to support participatory approaches that underpin the integration of revitalising heritage values. It is envisaged that through immersive design experiences students could gain a critical awareness of the realities, insight on regional success stories, an appreciation of limitations around conservation efforts, as well as a lasting memory of taking part in the design of integrated conservation projects. Faculty of the Built Environment (FBE), engenders learning activities appropriated with: conservation doctrines, community needs, sense of the cultural context of historic buildings. A pertinent concern during these undertakings was to initiate processes that instigate students' abilities to band together and work jointly with: students from two similar schools of thought at the faculty of Engineering and Built Environment (EBE), University of Cape Town (UCT) and School of Architecture and Design (SADE), Ardhi University (AU), in conjunction with African Architecture Matters, a non-profit consultancy firm working in fields of design planning, research and education. This paper thus seeks to highlight, from both socio-cultural inferences and historical perspectives, the significance of the learning opportunities for students, researchers and academics through adaptive reuse project of the oldest cinema in East Africa, the Majestic cinema.
\end{abstract}

Keywords: architectural education, built heritage, conservation, research, adaptive reuse, historic buildings.

\section{INTRODUCTION}

To be considered holistically, conservation of built heritage necessitates an integrated approach to its protection and enhancement. Professionals of the built environment across East Africa evidently place more attention to new developments and less to the possibility of restoration or adaptive reuse of historic buildings, a consequence that has partially stemmed from their educational background. Veritably, there has been a minimal collaboration between the architecture education sector vis-a-vis schools of architecture and practising professionals across Uganda. This divide widens a gap within which built heritage and conservation education would have thrived. Places and buildings around us have irreplaceable identities that are made up of social and cultural values that represent, embody and give significance to our societies [1]. Built heritage conservation education, from the onset, should entail a set of activities based on shared cultural values if sustainable solutions are to be realized [2], lest neglect or damage of historic buildings rooted on non-researched information. Heritage as a pedagogical resource for research and incorporated in teaching project-based work, allows students to understand it as symbolic, a physical and economic 
resource, platform for critical thinking and construction of new meanings [3]. This paper presents an appreciation of research-based design project as consideration for the thematic value of historic buildings.

Historians, from a social-cultural perspective and at an urban scale, have framed historic buildings in what Myers [4] coined as "Verandahs of Power" that drew inspiration from the physical verandahs of the House of Wonders in Arabic Beit-al-Ajaib (Fig. 1), an outstanding monument in Stone Town. The collapse of part of the House of Wonders in December 2020 was preceded by the collapse of the roof after heavy rainfall in November 2015. This was also preceded by the collapse of a corner section of the building (Fig. 2(a)) in 2012 leading to its closure.

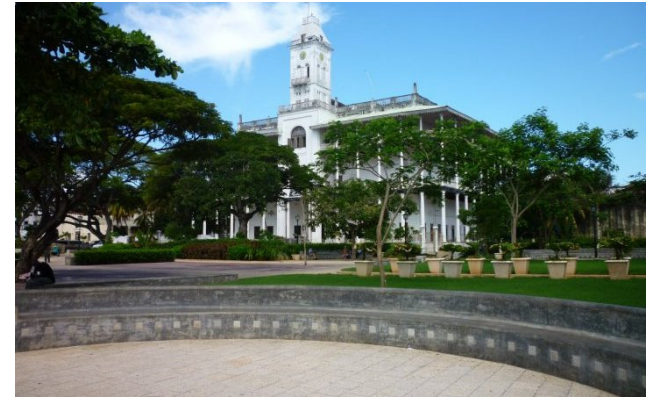

(a)

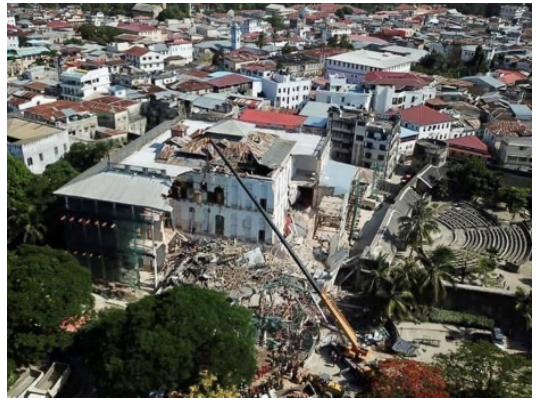

(b)

Figure 1: (a) House of Wonders [5]; and (b) House of Wonders in December 2020 [6].

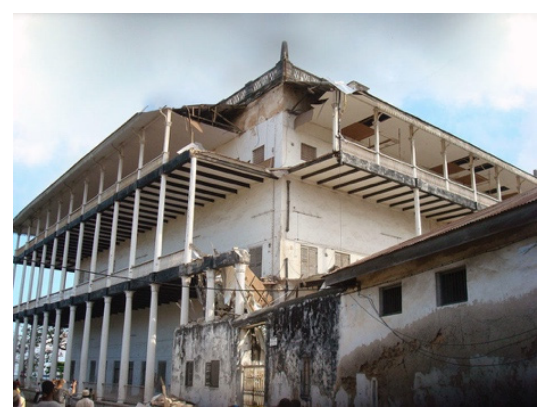

(a)

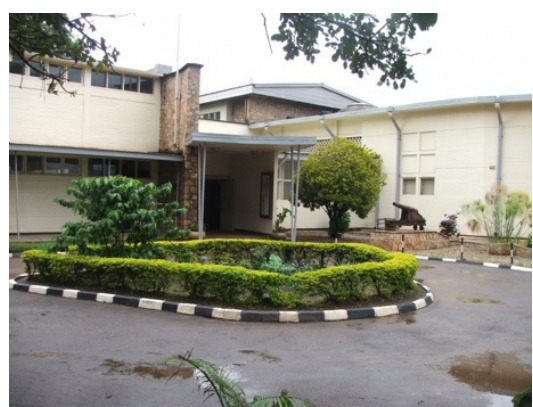

(b)

Figure 2: (a) Collapsed corner of the House of Wonders in 2012 [7]; and (b) The Uganda Museum [8].

The conundrum of the House of Wonders is relatable to the Uganda Museum (Fig. 2(b)) in that both buildings have been victims of neglect. The missed opportunities as a result of the limited partnership between the architectural education sector and the professionals have exacerbated this neglect. The case of disappearing heritage in East Africa and across subSaharan Africa is of little concern to a countless number of people. Related views that may apply to this situation can be observed in education, practice and society's perception of heritage. Inherent to this concern is the negative impact of socialization in architectural professional education in East Africa that overlooks society's desires and promotes sameness 
[9]. Partly because "many of the important African heritage sites are not known [...] or very few are declared World Heritage Sites" [10]. This narrative shall highlight principles of heritage conservation within architectural education that can be used as the basis to underscore the relevance of historic buildings. The rich historical past of East Africa with influences from Arabia, India, Persia, Portugal and in recent colonial times the western world, has left scattered gems worthy of restoration consideration. Teaching and learning in architecture education ought not to be limited to one single event but should be continuous throughout one's career. The scope and applicability of built heritage as a teaching tool should, therefore "[...] incorporate the past as a dynamic supply towards contemporary values" [3].

\section{GLOBAL PERSPECTIVES ON TEACHING CONSERVATION AND HERITAGE IN ARCHITECTURAL EDUCATION}

Incorporating heritage studies and conservation into architectural education is vital to the training of architecture students and later in their professional career. Needless to say, conservation is deeply engaged in the debate on sustainable practices in local contexts when our identities and control of our resources are progressively global [11]. From the beginning of the education career, various schools across the globe have introduced effective methodologies for teaching conservation education that may work and entail an approach through career structure [12]. Although there is a significant divide between practice and education, particularly in the field of architecture, in East Africa, "training for the purposes of executing tasks is a world apart from educating someone to develop critical thinking skills in how or why they would choose to execute a particular task" [11]. Further, the divide exists in gaps between different localised contexts, of which international organizations like UNESCO, ICCROM and ICOMOS have sought to bridge through various international methodologies and concepts, and challenged to rethink the meaning(s) of heritage and its values. Localizing such contexts demystifies the concept of scholarship in post-colonial societies across Africa as an invention of Western academia [13]. For architectural education to gradually contribute to the conservation profession, training should be carried out sequentially to integrate knowledge and understanding of the history of buildings [12] and, an introspective approach that portrays architecture education as philosophy as opposed to mere curriculum should be explored [14]. Application of methodologies and concepts, that apply to different types of buildings and are context-specific could be implemented. Architectural education then becomes paramount and provides a platform for re-interpreting any heritage evidence, re-evaluating history and reassessing places and values of any society as a whole.

\section{FBE'S PEDAGOGICAL SCHEME AND PLATFORM FOR ARCHITECTURAL EDUCATION}

Heritage and conservation-concerns are research areas that the FBE introduces to architecture students at an early stage. Historical issues are at the forefront of education and research at the faculty because of their relevance to the built environment, heritage and conservation. The research on heritage and conservation is not introduced as a chronological block course but as thematic design theories of historical and socio-cultural contexts of pre-19th-century human settlements across the globe. Hence, offering a grounded approach to historical studies that does not obscure readings of phenomenon [15]. In addition, these research studies emphasise the placement of historic places and buildings in their wider context that integrates sustainable development and their apprehension about the environment and climate responsiveness. Architecture, with its project-based education, varies from other traditional 
disciplines and does not imply a fundamental intellectual model [3]. As an outcome, the FBE has attempted to engage both learners and educators in a scheme of learning how to learn by socialization processes that are rooted in discursive environments whereby it is important to listen to students and appreciate their needs as they transition through their architecture education [16]. To further engage in the learning process and promote this research, the Field Experience travel exercise that was undertaken in 2020 by students proceeding to their 2 nd year focussed on documenting buildings across East Africa from the 1950s/1960s. As the students get to their advanced stages of the Bachelor of Environmental Design degree and/or proceed to postgraduate studies of Master of Architecture (Professional), some key research areas that have gleaned towards heritage and conservation have emerged over the past three years. The studio project, discussed in this paper, was undertaken by third-year finalist students of the Bachelor of Environmental Design. The bachelors program is the first stage of a two-tier architecture program at the faculty. The Master of Architecture program, which must be undertaken by students that have completed the bachelors program or its equivalent, has an entire course unit dedicated to adaptive reuse and conservation of historic buildings. In the same regard, the faculty of Engineering and the Built Environment (EBE) at the University of Cape Town, who were collaborative partners with FBE, have an honours program with an emphasis on heritage research among other study areas. EBE engaged in the previous collaborative-adaptive-Reuse-workshop with FBE and the University of Rwanda in 2019 that realised the importance of working with stakeholders, highlighted meaning(s) for the local context and added value to the built heritage of Kigali. Both EBE and FBE later carried on with the design project of the Majestic Cinema virtually because the site visit to Zanzibar was cancelled in March 2020 due to the global pandemic. Working remotely also extended to African Architecture Matters, who provided background historical information, drawings, photographs and availed time for video conferences.

\section{THE PROJECT}

\subsection{The building and its contribution to heritage and learning}

The Majestic Cinema building (Fig. 3) is not listed, however its context (Stone Town) was designated as a UNESCO World Heritage site in 2000. To fulfill UNESCO's requirements of World Heritage management standards, and resources and skills of Zanzibaris, adaptive reuse of designated buildings started with research and design at the forefront, and laid the groundwork. The research on this project began with understanding the culture of the Zanzibaris because "[...] the significance of an inhabited World Heritage site, cannot be fully understood, safeguarded and developed without considering the interest, dreams and

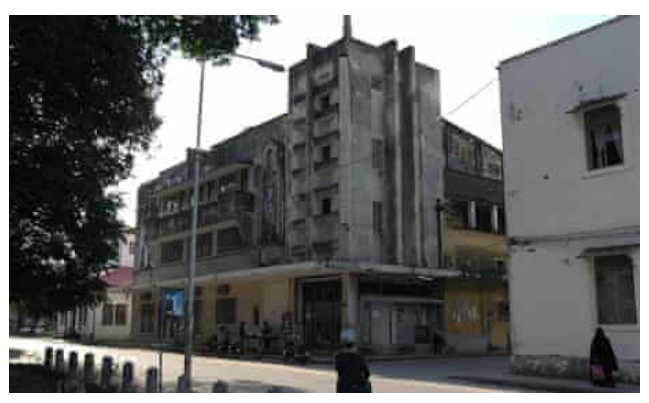

Figure 3: Majestic Cinema building in 2011 [18]. 
priorities of the inhabitants" [17]. Design exploration for the Majestic Cinema project began as discussions within the studio environment between instructors and students, as well as amongst students. This is often done to break the hierarchies of power and promote networks of interaction so as to downgrade what Olweny [9] posited as "[...] instructors in a position of authority could inculcate their views and values onto students, often with little contention."

The studio project thematically focussed on revitalization of the Majestic Cinema as an inclusive and sustainable model in which the new use of the building would be optimised for Zanzibar's communities and its cultural operators. Stakeholders (organizations) who would provide financial support during the planning and construction of the project were: Hifadhi Zanzibar, a coalition between the private sector and government; Reclaim Women Space, empowers women to work together to take back public space; Sauti Za Busara Zanzibar, celebrates African music under African skies; Zanzibar International Film Festival, one of the largest annual cultural events in East Africa; and African Architecture Matters. The project was intended to be the first 'culture hub' in Zanzibar, a place for various communities to meet, engage in dialogue and collaborate beyond the prevalent public spaces. In an increasingly mobile world, the project highlighted and contributed to ongoing debates around community heritage in lieu of students from Uganda and South Africa, and the communities in Zanzibar.

The majestic Cinema, built in the 1920s, derives its significance within the socio-cultural context as the first cinema in East Africa. From its inception, the cinema played an important role on the island, as an inclusive community space for Europeans, Indian, Arabs and indigenes. Located about 120 m west of the Creek Road (Fig. 4) that structured the urban sphere by absolute oppositions: Stone Town or "the city proper" and Ng'ambo the "Other Side" [19], the cinema then became an anchor space between the often forwarded "dual city" model of the colonial city in Africa [20].

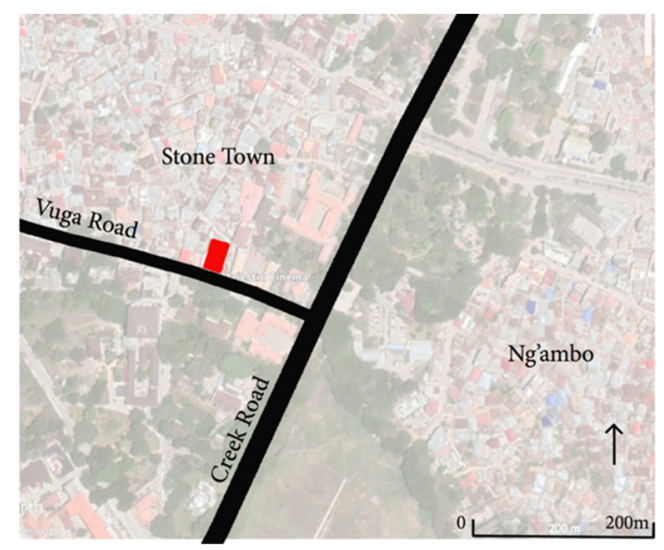

Figure 4: Location of Majestic Cinema. (Source: Author.)

\subsection{Value addition through adaptive reuse}

The redevelopment of the cinema into a self-sustaining Cultural Hub was chosen as a consequence of the myriad of cultures present in Zanzibar. The two student projects presented in this paper highlight the historic importance of the place and building's role, as an inclusive community space to Stone Town and the greater Zanzibar. Both projects aimed at; cultivating 
a sense of place through heritage ownership for the residents, achieving an integrated building program relevant to the stakeholders, and presented an operational management model strategy. As such, themes like "From Ruin to Rebirth: The Awakening of the Majestic" and "An architecture design where the dimensions of time in space are manifested to the user," were generated by students as a guide to the design.

The historic ambience embedded within the Majestic Cinema's spaces was given immediate care through the building program by the first student, Elizabeth Nabagerekka's proposal shown in Fig. 5(a). As a way of bringing this dilapidated building back to life, the program's target users were from within a $500 \mathrm{~m}$ radius from the cinema and these included: students from the State University of Zanzibar neighbouring the site to the east; and a public space, the Victoria Gardens south of the site.

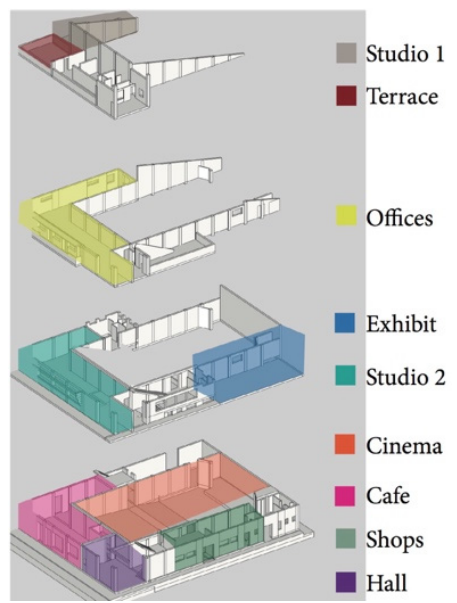

(a)

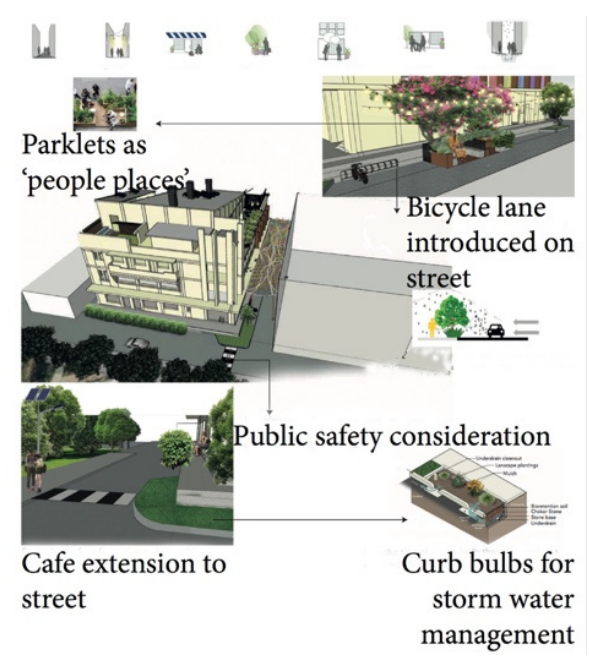

(b)

Figure 5: Building program proposal by Elizabeth Nabagerekka.

Nabagerekka's design proposal sought to activate the streets (Fig. 5(b)) along Vuga Road and that adjacent to the university, and took advantage of the public park through activities such as open-air movie shows, public gatherings for cinema sensitization, public art and furniture. Activities such as these contribute to the revitalization of the cinema as a cultural hub through the space program and thus highlighting the contextual relationship.

The second student, Ronald Businge pursued an aesthetic approach to the revitalization of the cinema building in an attempt to capture its historic highlights as dimensions of time manifested to the users through material selection. The old and the new materials were represented by a palette (Fig. 6) that overtly merged them, and bridged the past, present and future anticipation. The cinema's role in this case became a seamless continuum with the bygone and a diverse multi-dimensional cinema spatial experience introduced at the roof top of the building (Fig. 7)

Businge's proposal used the form, facades and structure to further anchor old building elements into a bold modern bone: an attempt to maintain authenticity of the cinema - pay homage to the past; and cultural hub - showcase the future expression. The bold modern bone 


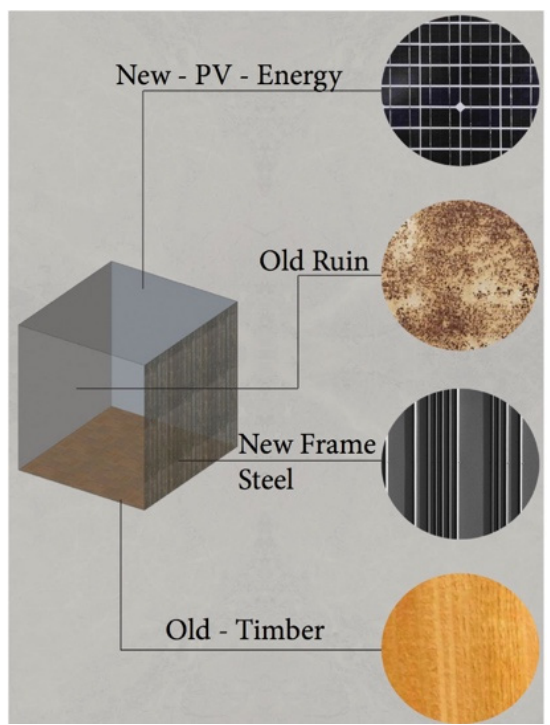

Figure 6: Interior ideas by Ronald Businge.

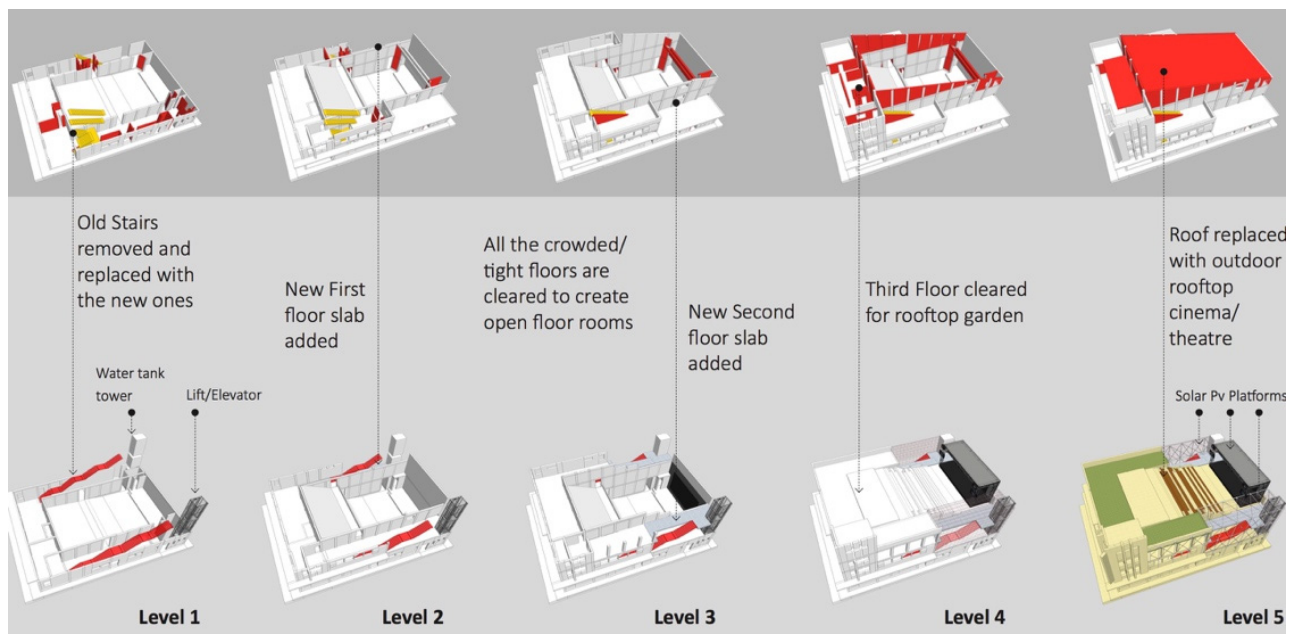

Figure 7: Old vs new interventions by Ronald Businge.

was represented by a steel structure that braced and encased part of the building (Fig. 8), an endeavour that resulted from engaging research at the onset of the assignment. Both projects showcased steps towards approaches to sustainability concerns such as social sustainability: participatory processes; and environmental sustainability: bioclimatic design. Such approaches are within FBE's goal to educate professionals who contribute to cultural and socio-economic development through participation in design, construction and interpretation of built environments. 


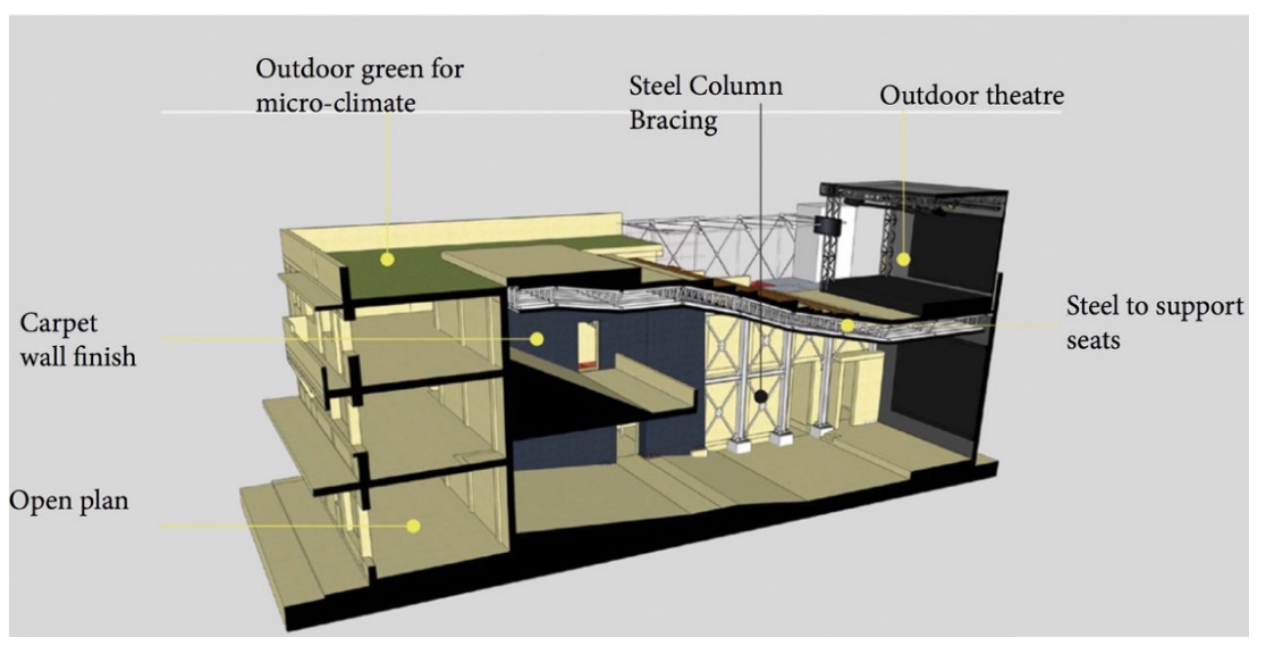

Figure 8: Section perspective by Ronald Businge.

\section{CONCLUSION}

Conservation of built heritage by paying homage to the past through architectural education can serve as a worthwhile role in the evolution of the built environment. Education, like conservation, is characterised by constant change and the study of history as a pertinent component of built heritage provides static platforms from which to draw inferences. Global standpoints of the most appropriate approach towards conservation education in architecture ought to be tailored towards specific historical narratives, socio-cultural extrapolations and highlight sustainable practices. Unravelling strategies for critical practice should be vested in both trivial subversions of prejudiced opinions [21], and questioning notions of the past and present. Notions such as the basic cultural practices that have been operational throughout, and housed within the lifeblood of historic buildings should be investigated. Even though there is disregard for historic buildings in East Africa, partly as a consequence of Moon's [22] assertion on ownership conflicts and heritage interpretation, architectural education is beginning to have a subtle influence on the awakening towards heritage. Although the students did not physically travel to Zanzibar in March 2020 for the ground-work studies, the design proposals were well received by the different stakeholders, with positive feedback, and are to be showcased at the Zanzibar International Film Festival in March 2021.

\section{ACKNOWLEDGEMENTS}

Seven students participated in the Zanzibar project, two of whom had their work included in the paper: Elizabeth Nabagerekka and Ronald Businge. We would like to acknowledge students from the FBE whose research areas have contributed to conservation and built heritage studies in the last five years. These study areas at undergraduate level included: Conservation of Modernist Industrial Heritage in Kampala: Case Study of the Uganda Coffee Marketing Board (Diana Amanya Kacooni) and Heritage Significance of Late 19th and early 20th Century Buildings in Buganda Kingdom, Uganda (Gilbert Kafuuma and Esther Muhwezi); and at postgraduate level they included: Making a Case for Tropical Modernism as Built Heritage in Uganda (Joseph Kasimbi) and A Historical Study of Jinja, Uganda: A City Influenced by Industrial Developments During the Early 20th Century (Anthony K. Wako). 


\section{REFERENCES}

[1] Worthing, D. \& Bond, S., Managing Built Heritage: The Role of Cultural Significance, John Wiley \& Sons, 2008.

[2] Cody, J. \& Fong, K., Built heritage conservation education. Built Heritage, 33(3), pp. 265-274, 2007.

[3] Lapadula, M. \& Quiroga, C., Heritage as a pedagogical resource and platform for exploration in architectural design education. Journal of Architecture, 17(4), pp. 591607, 2012.

[4] Myers, G.A., Verandahs of Power: Colonialism and Space in Urban Africa, Syracuse University Press, 2003.

[5] Iconic house of wonders collapses leaves Zanzibaris wondering about fate of cultural heritage. https://globalvoices.org/2020/12/28/iconic-house-of-wonders-collapseleaves-zanzibaris-wondering-about-fate-of-cultural-heritage/. Accessed on: 21 Jan. 2021.

[6] Oman: Collapse of House of Wonders to be investigated. https://gulfnews.com/world/ gulf/oman/oman-collapse-of-house-of-wonders-in-zanzibar-to-be-investigated1.76124462. Accessed on: 21 Jan. 2021.

[7] World Monuments Fund. https://www.wmf.org/project/house-wonders-and-palacemuseum. Accessed on: 10 Jan. 2021.

[8] Yamarella: An armchair travel blog that takes you around the world. https://yamarella.wordpress.com/2017/08/08/visiting-uganda/. Accessed on: 20 Jan. 2021.

[9] Olweny, M., Socialisation in architecture education: A view from East Africa education and training. Education+Training, 59(2), pp. 188-200, 2017.

[10] Rüther, H., An African heritage database the virtual preservation of Africa's past. International Archives of the Photogrammetry, Remote Sensing and Spatial Information Sciences, 34(Pt 6), p. W6, 2002.

[11] Cody, J. \& Fong, K., Built heritage conservation education. Built Heritage, 33(3), pp. 265-274, 2007.

[12] Jokilehto, J., An international perspective to conservation education. Built Heritage Conservation Education, 33(3), pp. 275-286, 2007.

[13] Marschall, S., The heritage of post-colonial societies. The Ashgate Research Companion to Heritage and Identity, eds B. Graham \& P. Howard, Ashgate Publishing: Hampshire, pp. 347-364, 2008.

[14] Embaby, M., Heritage conservation and architectural education: An education methodology for design studios. HBRC Journal, 10(3) pp. 339-350, 2014.

[15] Arnold, D. (ed.), Reading Architecture History, Routledge: London, pp. 1-14, 2002.

[16] Olweny, M., Listen without prejudice: The design studio as a discursive environment (or) Helping students learn in architecture education. Presented at Association of Collegiate Schools of Architecture 108th Annual Meeting, San Diego, 2020.

[17] Mathisen, B., East Africa world heritage network and stakeholder priorities. International Journal of Heritage Studies, 18(3), pp. 332-338, 2012.

[18] Tanzania's art deco ruins the Majestic Cinema, inspires restoration campaign. The Guardian. https://www.theguardian.com/world/2011/jun/02/zanzibar-mjaesticcinema-restoration-campaign. Accessed on 31 Dec. 2020.

[19] Bissell, W.C., Urban Design, Chaos, and Colonial Power in Zanzibar, Indiana University Press, 2011.

[20] Beeckmans, L., Editing the African City: Reading planning in Africa from a comparative perspective. Planning Perspectives, 28(4), pp. 615-627, 2013. 
PI-38 Structural Studies, Repairs and Maintenance of Heritage Architecture XVII

[21] Wigglesworth, S., Critical practice. The Journal of Architecture, 10(3), pp. 335-346, 2005. https://doi.org/10.1080/13602360500162238.

[22] Moon, K., Ownership conflicts and heritage interpretation in Uganda and Tanzania. 8th Annual International Symposium in Heritage Interpretation, US/ICOMOS, 2005. 